\title{
Development and characterization of a new conducting carbon composite electrode
}

\author{
Madalina M. Barsan ${ }^{\mathrm{a}}$, Edilson M. Pinto ${ }^{\mathrm{a}}$, Monica Florescu ${ }^{\mathrm{b}}$, Christopher M.A. Brett ${ }^{\mathrm{a}, *}$ \\ a Departamento de Química, Faculdade de Ciências e Tecnologia, Universidade de Coimbra, 3004-535 Coimbra, Portugal \\ ${ }^{\mathrm{b}}$ Department of Physics, Technological Engineering Faculty, 500068 Brasov, Romania
}

\section{A R T I C L E I N F O}

\section{Article history:}

Received 14 October 2008

Received in revised form 5 January 2009

Accepted 7 January 2009

Available online 14 January 2009

\section{Keywords:}

Graphite

Cellulose acetate

Composite electrode

Neutral red

Ascorbate

\begin{abstract}
A B S T R A C T
A new conducting composite flexible material prepared from cellulose acetate (CA) polymer and graphite has been developed and used for the fabrication of electrodes, which were then characterized by cyclic voltammetry and electrochemical impedance spectroscopy. Scanning electron microscopy (SEM) was used to provide information concerning the morphology of the composite electrode surface. The potential window, background currents and capacitance were evaluated by cyclic voltammetry in the $\mathrm{pH}$ range from 4.6 to 8.2. The voltammetry of model electroactive species demonstrates a close to reversible electrochemical behaviour, under linear diffusion control. The electroactive area of the composite electrodes increases after appropriate electrode polishing and electrochemical pre-treatment. The electrodes were used as substrate for the electropolymerisation of the phenazine dye neutral red, for future use as redox mediator in electrochemical biosensors. The composite electrodes were also successfully used for the amperometric detection of ascorbate at $0.0 \mathrm{~V}$ vs. SCE, and applied to the measurement of ascorbate in Vitamin C tablets; the sensor exhibits high sensitivity and a low detection limit of $7.7 \mu \mathrm{M}$. Perspectives for use as a versatile, mechanically flexible and robust composite electrode of easily adaptable dimensions are indicated.
\end{abstract}

(c) 2009 Elsevier B.V. All rights reserved.

\section{Introduction}

Electrodes composed from conducting material in insulating binder were first developed by Adams and co-workers in 1958, when he published his pioneering work concerning a new carbonbromoform paste electrode [1]. Since then, different procedures have been developed to manufacture carbon paste electrodes. These conducting composite materials could be considered to be random assemblies of minielectrodes, in which "edge effects" contribute significantly to the Faradic current. The conductive parts of the arrays have different sizes and shapes, and it is this randomness that prevents theoretical models based on homogeneously distributed discs, to be used to describe the composite electrode behaviour $[2,3]$. Using different types of carbon, entrapped in a suitable, normally polymeric, binder, various carbon paste electrodes have been extensively used in electroanalytical measurements [4,5]. Composite electrodes can offer many potential advantages compared to more traditional electrodes consisting of a single conducting phase, such as glassy carbon, platinum or gold. They can be fabricated with great flexibility in various sizes and shapes, being easy to adapt to desired systems [6] and have a great advantage in the biosensor

\footnotetext{
* Corresponding author. Tel.: +351 239 835295; fax: +351 239835295.

E-mail address: brett@ci.uc.pt (C.M.A. Brett).
}

area, being easily modifiable, permitting the incorporation of different filler components, e.g. enzymes, cofactors, mediators, catalysts etc [7-10].

Among composite materials, solid graphite composite electrodes have useful characteristics such as a good signal to noise ratio, high mechanical resistance, relative simplicity in preparation and surface renewal and low fabrication cost [11]. Much has been published about poly-vinyl chloride (PVC) - graphite composite electrodes, with application to trace metal detection [12], determination of antioxidants using a flow injection amperometric system [13], dopamine, ascorbic acid and uric acid detection [14] or alditol monitorization using a nickel oxide chemically modified PVC-C composite electrode [15]. Alegret and co-workers successfully used epoxy-resin binder to build epoxy-graphite composite electrodes as substrates for biosensor construction, such as a bacterial cell biosensor for phenol determination [16]. Biosensors based on gelatine membranes containing carboxyl esterase or alcohol oxidase for aspartame and ethanol detection [17], a protein A biosensor for electrochemical immunosensing [18] and also transducers for hybridisation genosensors [19] have been developed.

Cellulose acetate (CA) has been successfully used for the fabrication of membranes containing different biomolecules or redox compounds as well as for the fabrication of size-exclusion membranes to increase the selectivity of electrochemical sensors [20]. For example, a CA membrane was employed to entrap ferrocene 
during the construction of a mediated fructose biosensor, in this way resolving the problem of ferrocene leaching from the electrode [21], for the fabrication of a peroxide biosensor with horseradish peroxidase enzyme and dimethylferrocene mediator embedded in a CA membrane [22] or for the construction of an ascorbate sensor containing a cellulose acetate polymeric film bearing 2,6dichlorophenolindophenol [23]. Another promising application of CA was published by Gushikem and co-workers [24], in which CA was used in the preparation of a methylene blue-zirconium phosphate hybrid membrane successfully employed for the electrocatalytic oxidation of NADH.

In this work, a new conducting flexible, composite material based on graphite and cellulose acetate insulating polymer was developed was used for the fabrication of electrodes, which were then characterized using cyclic voltammetry and electrochemical impedance spectroscopy. The electrodes served also as a substrate material for the electropolymerisation of the phenazine dye neutral red in order to obtain and characterise a film of the electroactive polymer poly(neutral red), which has been successfully used in our laboratory as a mediator in the construction of biosensor assemblies $[25,26]$. Application to the determination of ascorbate is demonstrated.

\section{Experimental}

\subsection{Reagents and buffer electrolyte solutions}

All reagents were of analytical grade and were used without further purification. Cellulose acetate $(\approx 40 \%$ acetyl content), hexaammineruthenium(III) chloride, sodium phosphate monobasic monohydrate and ascorbic acid were from Sigma-Aldrich, Germany. Acetone, cyclohexanone, neutral red (NR), 65\% dye content, potassium hexacyanoferrate(II) trihydrate and potassium nitrate were obtained from Fluka, Switzerland. Potassium hydrogen phosphate, acetate, acetic acid, di-sodium hydrogen phosphate 2-hydrate and sodium chloride were from Riedel-deHaën, Germany. Potassium hydrogen phosphate 3-hydrate was from Panreac, Spain. Standard solutions of $5 \mathrm{mM}$ hexaammineruthenium(III) chloride and $3 \mathrm{mM}$ potassium hexacyanoferrate(II) were prepared by dissolving the salts in $0.1 \mathrm{M}$ potassium chloride electrolyte solution.

Graphite powder of diameter approximately $30 \mu \mathrm{m}$ was obtained from spectroscopic electrodes graphite bars type SW. 104 produced by the "Kablo Bratislava", National Corporation ("Electrocarbon Topolcany” Factory, Slovakia).

Buffer solutions, of $\mathrm{pH}$ values 4.6, 5.5, 7.0 and 8.2, were acetate buffer $\mathrm{pH} 4.6$, prepared by mixing $0.2 \mathrm{M}$ sodium acetate with $0.2 \mathrm{M}$ acetic acid, $0.025 \mathrm{M}$ potassium phosphate saline buffer (KPBS) pH 5.5, prepared from potassium hydrogen phosphate and di-potassium hydrogen phosphate 3-hydrate with the addition of $0.1 \mathrm{M}$ potassium nitrate and $\mathrm{pH} 7.0$ and 8.2 solutions were $0.1 \mathrm{M}$ sodium phosphate saline (NaPBS) prepared from di-sodium hydrogen phosphate 2-hydrate and sodium phosphate monobasic monohydrate with the addition of $0.05 \mathrm{M}$ sodium chloride.

The solution used for the electropolymerisation of NR contained $1 \mathrm{mM} \mathrm{NR}$ in $0.025 \mathrm{M} \mathrm{KPBS}$ pH 5.5 buffer solution, as described above.

The samples used for ascorbate determination were commercial Cecrisina ${ }^{\circledR}$ (Janssen-Cilag, Portugal) effervescent vitamin $\mathrm{C}$ tablets (1.0 g).

Millipore Milli-Q nanopure water (resistivity $\geq 18 \mathrm{M} \Omega \mathrm{cm}$ ) and analytical reagents were used for the preparation of all solutions. Experiments were performed at room temperature $\left(25 \pm 1^{\circ} \mathrm{C}\right)$.

\subsection{Apparatus}

A three-electrode electrochemical cell of volume $10 \mathrm{~cm}^{3}$ was used, containing the composite electrode as working electrode, a platinum foil counter electrode and a saturated calomel electrode (SCE) as reference.

All electrochemical measurements were performed using a computer-controlled $\mu$-Autolab Type II potentiostat-galvanostat running with GPES (general purpose electrochemical system) for Windows version 4.9 software (EcoChemie, Utrecht, Netherlands).

The electrochemical impedance measurements were carried out on a PC-controlled Solartron 1250 frequency response analyser, coupled to a Solartron 1286 electrochemical interface using ZPlot 2.4 software (Solartron Analytical, UK). A rms perturbation of $10 \mathrm{mV}$ was applied over the frequency range $65 \mathrm{kHz}-0.1 \mathrm{~Hz}$, with 10 frequency values per decade. The spectra were recorded within a potential range from -0.8 to $+0.8 \mathrm{~V}$ vs. SCE.

The pH-measurements were carried out with a CRISON 2001 micro pH-meter (Crison, Spain) at room temperature.

Microscope images were acquired with a scanning electron microscope Philips XL-30 FEG scanning electron microscope, equipped with a thermionic field emission SEM with an electronically-controlled automatic gun. All images were captured at $15 \mathrm{kV}$.

\subsection{Preparation of the composite electrodes}

A cellulose acetate gel was prepared by dissolving cellulose acetate $5-15 \%(w / v)$, in the optimised procedure $15 \%(w / v)$, in a mixture of solvents containing $55 \%(\mathrm{v} / \mathrm{v})$ acetone and $45 \%(\mathrm{v} / \mathrm{v})$ cyclohexanone. Graphite-embedded composite was then prepared by adding $10-20 \% \mathrm{w} / \mathrm{v}$ graphite powder (optimised at $15 \%(\mathrm{w} / \mathrm{v})$ ) to the obtained CA gel, mixing continuously. The homogenous graphite suspension obtained was allowed to dry for at least $24 \mathrm{~h}$ in a Petri dish and removed as a thick foil of thickness $\sim 0.7 \mathrm{~mm}$, and was then cut into square pieces of $5 \mathrm{~mm} \times 5 \mathrm{~mm}$. External electrical contact was made on the rear surface by a copper wire glued with silver paint; the whole rear face was then covered with insulating epoxy resin. In this way electrodes of geometric area $0.25 \mathrm{~cm}^{2}$ were obtained.

Poly(neutral red) (PNR) phenazine polymer was prepared as a film on the CA-graphite composite electrode substrate by cyclic voltammetry in the buffer solution described in Section 2.1, containing $1 \mathrm{mM}$ monomer, at a scan rate of $50 \mathrm{mV} \mathrm{s}^{-1}$. The potential was cycled between -1.0 and $+1.0 \mathrm{~V}$ vs. SCE for 15 cycles, according to procedures previously optimised in $[25,26]$.

\subsection{Electrode pre-treatment}

Before cyclic voltammetry measurements, electrodes were pretreated as follows. Composite electrodes were polished on abrasive paper and regular paper and then electrochemically pre-treated by applying a fixed potential of $+0.9 \mathrm{~V}$ vs. SCE and then by cycling the potential in the range from -1.5 to $1.5 \mathrm{~V}$ vs. SCE at a scan rate of $100 \mathrm{mV} \mathrm{s}^{-1}$ in the supporting electrolyte to be employed until a reproducible voltammetric curve was recorded (usually after five cycles).

\section{Results and discussion}

\subsection{Optimisation of the composite material}

The material composition was first optimized by varying the amount of both components, cellulose acetate insulating polymer and graphite, see Table 1 . The composite containing $10 \% \mathrm{w} / \mathrm{v}$ of CA and graphite, exhibited a high electrical resistivity. It was attempted to improve the conductivity by increasing the percentage of graphite and/or decreasing the proportion of CA insulating polymer, but large changes led to easily breakable electrodes. The composite containing $15 \% \mathrm{w} / \mathrm{v}$ cellulose acetate and $15 \% \mathrm{w} / \mathrm{v}$ 
Table 1

Percentage values $(\mathrm{w} / \mathrm{v})$ of cellulose acetate and graphite used for fabrication of different composite materials; solvent composition: $55 \%(\mathrm{v} / \mathrm{v})$ acetone and $45 \%(\mathrm{v} / \mathrm{v})$ cyclohexanone.

\begin{tabular}{lrrrrrr}
\hline Graphite (\%) & 10 & 10 & 10 & 15 & 15 & 20 \\
Cellulose acetate (\%) & 10 & 7 & 5 & 7 & 15 & 7 \\
\hline
\end{tabular}

graphite (in a solvent of $55 \% \mathrm{v} / \mathrm{v}$ acetone and $45 \% \mathrm{v} / \mathrm{v}$ cyclohexanone) showed a lower resistivity than $10 \% \mathrm{CA} / 10 \%$ graphite with a greater compactness, and thence smaller distance between the graphite particles. It exhibited the best compromise between electrical conductivity and rigidity and was therefore chosen for the fabrication of further electrodes.

With the objective of preparing composite materials for use as substrates for mediated-biosensor construction, $0.1 \%$ by mass neutral red redox active phenazine monomer was also added to the conducting CA-graphite material. Electrodes made with this material were tested in $0.1 \mathrm{M} \mathrm{KCl}$ solution by cyclic voltammetry and it was observed that the monomer exhibited very low electroactivity, probably because of the low amount exposed directly to the electrolyte solution. This approach was therefore not pursued further.

\subsection{Scanning electron microscopy (SEM) characterisation of the composite.}

SEM images can provide information about the structure, size and distribution of graphite particles in the matrix of the CA polymer and for examining the morphology of the electrode surface.

Fig. 1. shows scanning electron micrographs of a CA-graphite composite electrode, pre-treated as described in the experimental section. The electrode surface is heterogeneous, with lighter areas, associated with the CA insulating polymer, and darker areas, corresponding to the graphite conducting micro-structures. The electrochemical performance of the composite electrodes is strongly affected by the presence of the insulator matrix of the CA polymeric binder, which coats the graphite particles, at the same
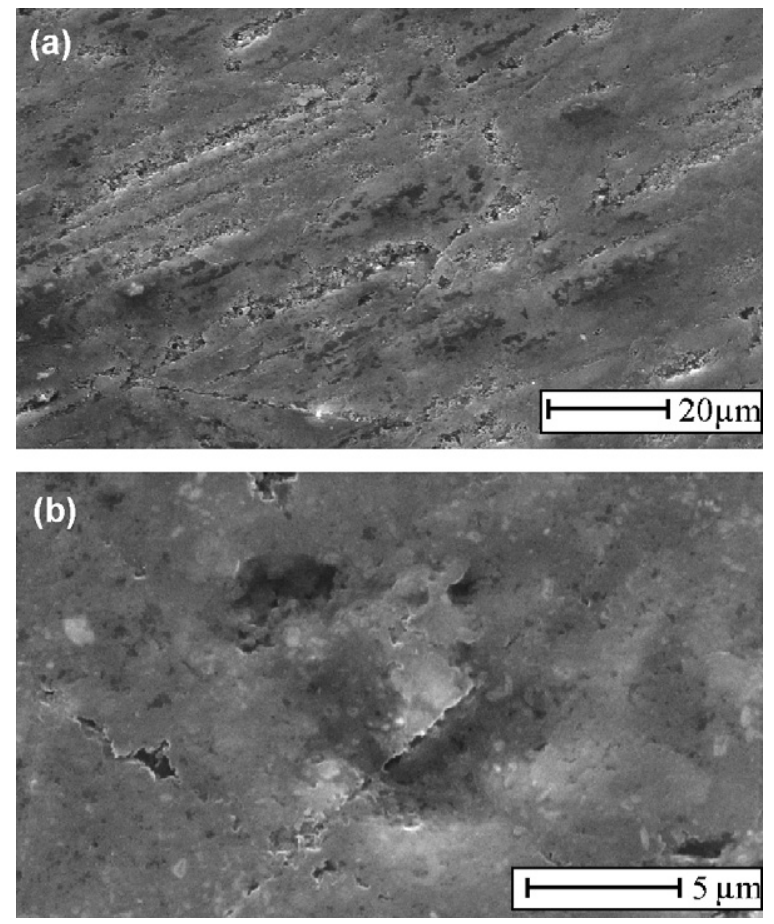

Fig. 1. Scanning electron micrographs of mechanically-polished conducting CA-graphite composite electrodes at different resolutions (b) is a detail of (a) at higher magnification. time increasing electrode resistivity which is influenced by the distance between the particles. Since it is known that a low rate of evaporation of the solvents provides the smoothest surfaces, the material was dried at low temperatures of $\approx 20^{\circ} \mathrm{C}$.

The scratches observed in Fig. 1 are produced during electrode polishing, done in order to remove the excess of CA polymer and to make the electrode surface uniform. No islands of graphite are observed in the polymer matrix. The SEM images clearly demonstrate the roughness and some porosity of the electrode surface, the pores having a dimension below $5 \mu \mathrm{m}$. Both these factors may increase the electroactive area of the composite electrode.

\subsection{Potential range and background currents}

In order to determine the potential window and the capacitance of the composite electrodes, a voltammetric study at different scan rates was performed in various buffer solutions with $\mathrm{pH}$ values from 4.6 to 8.2: $0.1 \mathrm{M}$ acetate buffer $\mathrm{pH} 4.6,0.025 \mathrm{M}$ KPBS pH 5.5, $0.1 \mathrm{M}$ NaPBS pH 7 and NaPBS pH 8.2 (see Fig. 2). Cyclic voltammograms recorded in $0.1 \mathrm{M}$ NaPBS pH 7.0 at composite electrodes (Fig. 2c) showed a good reproducibility for the background currents, with a calculated relative standard deviation of $\sim 4 \%$. Electrodes exhibited a slightly lower hydrogen overvoltage and similar positive limits due to oxygen evolution compared with carbon film electrodes [27].

Accessible ranges of potential and electrode capacitances are shown in Table 2. The overall potential window of graphite CA composite electrodes is $2.8 \pm 0.2 \mathrm{~V}$ vs. SCE, larger than the values reported for most carbon-based composite electrodes [3,12,14,28]. As can be seen in Fig. 2, in neutral and basic solutions, the potential window is larger. Surface polishing and electrochemical pre-treatment increased the potential window of the composite electrodes by $\sim 0.6 \mathrm{~V}$ vs. SCE but did not influence the capacitance values of these electrodes.

\subsection{Composite electrode kinetics and sensitivity}

Standard electroactive species were used to characterise the electrochemical behaviour of the composite electrodes. Cyclic voltammetry was performed in potassium hexacyanoferrate(II) and hexaammineruthenium(III) chloride solutions for scan rates from 10 to $200 \mathrm{mV} \mathrm{s}^{-1}$. Well-defined anodic and cathodic peaks were recorded for both redox couples, Fig. $3 \mathrm{a}_{1}, \mathrm{a}_{2}$. Voltammogram shapes are slightly affected by the scan rate and both cathodic and anodic peak currents depend linearly on the electroactive species concentration $\left(r^{2}=0.998\right)$ (data not shown) and with the square root of the scan rate $\left(r^{2}=0.999\right)$ over the whole range of scan rates examined, Fig. $3 b_{1}, b_{2}$, indicating that the processes are diffusion-controlled. In both cases, the linear relationship was not influenced either by the direction of changes in concentration or by the scan rate, revealing the absence of memory effects concerning interaction of the species with the electrode surface.

Comparing the cyclic voltammograms presented in Fig. $3 \mathrm{a}_{1}, \mathrm{a}_{2}$ it is seen that after polishing the electrodes, the cyclic voltammograms recorded in solutions with $\mathrm{Ru}^{\mathrm{III}}$ or $\mathrm{Fe}^{\mathrm{II}}$ both presented better defined, sharper peaks with a smaller peak separation, suggesting an increase in the electrochemical reversibility.

As can be observed by comparing the slopes of the curves, after polishing the electrode the kinetics of the electron transfer at the composite electrode surface were improved, for both anodic and cathodic processes, probably because part of the insulating polymer is removed and, at the same time, the homogeneity of the electrode surface is increased. Further polishing does not lead to any more improvement in electrode sensitivity. The values of $I_{\mathrm{pa}} / I_{\mathrm{pc}}$ were very close to unity for both redox couples, indicative of electrochemically quasi-reversible systems. 

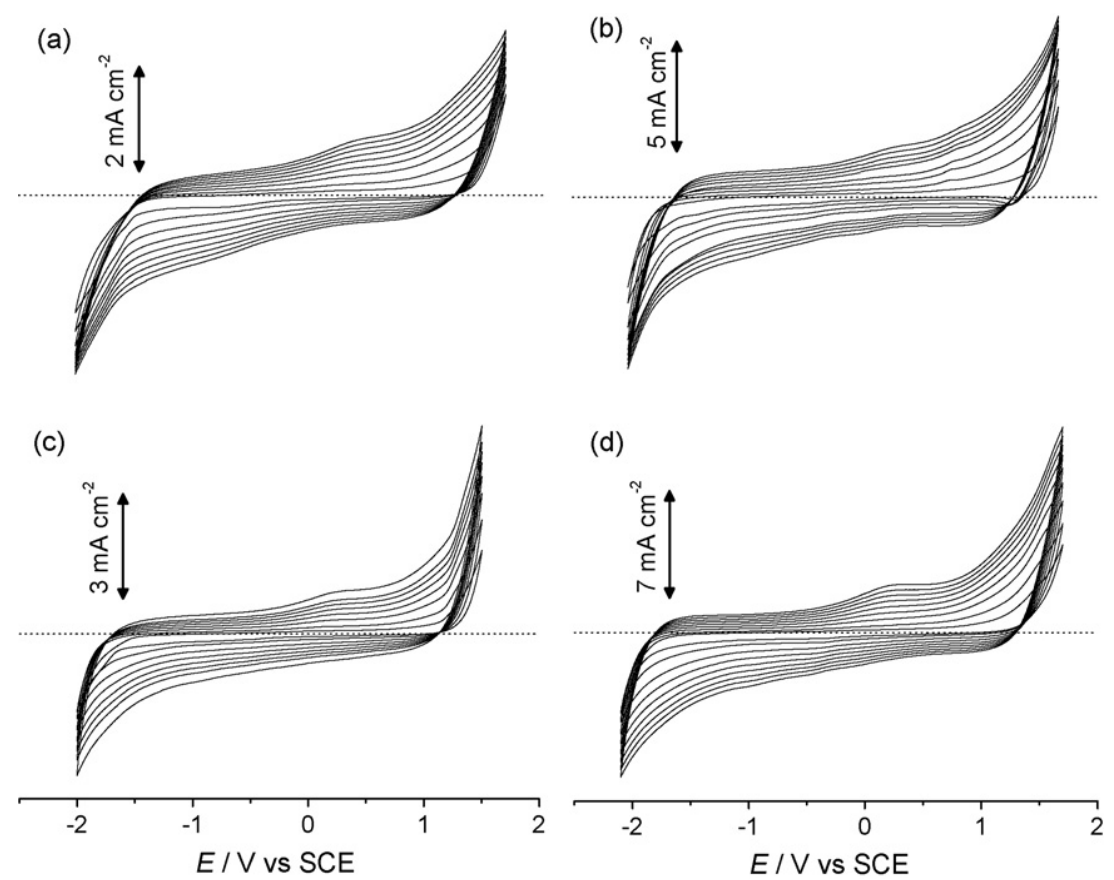

Fig. 2. Cyclic voltammograms recorded at composite electrodes in the scan rate range from 10 to $200 \mathrm{mV} \mathrm{s}^{-1}$ in different buffer solutions (a) acetate buffer $\mathrm{pH} 4.6$, (b) $0.025 \mathrm{M}$ KPBS pH 5.5, (c) $0.1 \mathrm{M}$ NaPBS pH 7.0 and (d) $0.1 \mathrm{M} \mathrm{NaPBS}$ pH 8.2.

Table 2

Potential window and normalised capacitance values of composite electrodes determined from cyclic voltammograms recorded at scan rates from 10 to $200 \mathrm{mV} \mathrm{s}^{-1}$ in various buffers, pH between 4.6 and 8.2.

\begin{tabular}{|c|c|c|c|c|}
\hline Buffer solution & Acetate (pH 4.6) & KPBS (pH 5.5) & NaPBS (pH 7.0) & NaPBS (pH 8.2) \\
\hline $\begin{array}{l}\text { Potential window } / \mathrm{V} \text { vs. SCE } \\
\text { Capacitance } / \mathrm{mF} \mathrm{cm}^{-2}\end{array}$ & $\begin{array}{l}-1.4 \text { to }+1.2 \\
4.8\end{array}$ & $\begin{array}{l}-1.5 \text { to }+1.2 \\
10.0\end{array}$ & $\begin{array}{l}-1.7 \text { to }+1.1 \\
5.2\end{array}$ & $\begin{array}{l}-1.7 \text { to }+1.3 \\
12.4\end{array}$ \\
\hline
\end{tabular}
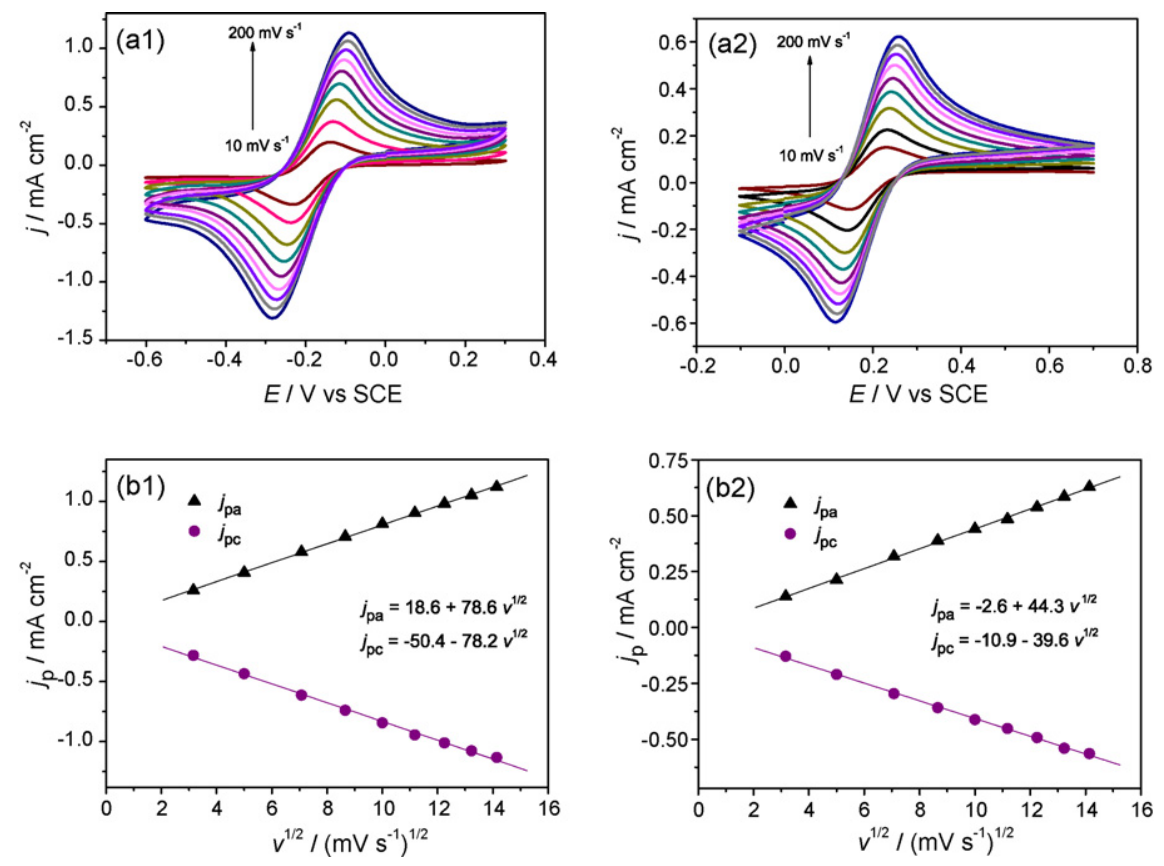

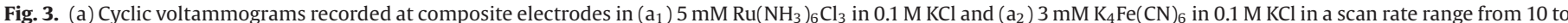

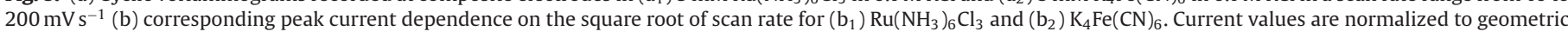
areas. 
For scan rates between 10 and $200 \mathrm{mV} \mathrm{s}^{-1}$ at polished electrodes, the calculated slope of the plot of $\log j$ vs. $\log v$ is $0.496 \pm 0.006\left(r^{2}=0.999\right)$ for hexaammineruthenium(III) and $0.507 \pm 0.007\left(r^{2}=0.999\right)$ for hexacyanoferrate(II), close to the value of 0.5 for an ideal process, under linear diffusion conditions [29]. Previous investigations have demonstrated that the voltammetric response of rigid conducting composites is similar to that of a microelectrode array, so that the nature of the diffusion field should depend on the experimental timescale: linear diffusion towards each individual microzone should predominate at short times. For intermediate timescales, radial diffusion due to the spherical diffusion field around each microzone is the predominant one. For sufficiently long experimental timescales, the graphite particles' response are not independent of each other because of the overlapping of diffusion fields from the conducting particles of the composite electrode and the electrode can be viewed as a uniform and continuous surface for a diffusion-controlled electrochemical process $[2,30]$.

The difference between anodic and cathodic peak potential values was larger than the ideal value of $57 \mathrm{mV}$ for fast electrode kinetics and increased slightly with increasing scan rate, following the equations $\Delta E(\mathrm{mV})=92.2+0.48 \times v\left(\mathrm{mV} \mathrm{s}^{-1}\right)\left(\mathrm{Ru}^{\mathrm{III}} / \mathrm{Ru}^{\mathrm{II}}\right)$ and $\Delta E(\mathrm{mV})=76.5+0.31 \times v\left(\mathrm{mV} \mathrm{s}^{-1}\right)\left(\mathrm{Fe}^{\mathrm{II}} / \mathrm{Fe}^{\mathrm{III}}\right)$. Several factors may contribute to this increased peak splitting. The first is the negatively-charged nature of the carbon based composite electrode surface which slows down electrode kinetics [31], secondly the relatively high resistance of the material itself and thirdly the porosity/roughness of the electrode surface (see Section 3.2), which may lead to extra electroactive species within the pores of the composite material. In agreement with this, the reaction kinetics of the electroactive species in concentrated solutions may be slowed due to the slow mobility of the molecules [32].

Finally, a low variability was observed in the electrochemical response of the polished CA-graphite composite electrodes, giving a relative standard deviation (RSD) of the measured peak current values lower than $4 \%$, suggesting good homogeneity of the composite mixture.

Table 3 contains the values of calculated electroactive areas $(A)$ and the percentage of the geometric area $\left(A^{\prime}\right)$ of the CA-graphite composite electrodes, determined using the Randles-Sevčik equation, using both redox species. The diffusion coefficients were calculated using chronoamperometry as referred to in [33] in the same solution used to calculate the electroactive areas: $5 \mathrm{mM}$ hexaammineruthenium(III) chloride in $0.1 \mathrm{M} \mathrm{KCl}$ and $3 \mathrm{mM}$ potassium hexacyanoferrate(II) in $0.1 \mathrm{M} \mathrm{KCl}$. The values obtained were $6.1 \times 10^{-6} \mathrm{~cm}^{2} \mathrm{~s}^{-1}$ for hexacyanoferrate(II) and $9.0 \times 10^{-6} \mathrm{~cm}^{2} \mathrm{~s}^{-1}$ for hexaammineruthenium(III). The electroactive areas $(A)$ were also calculated before and after polishing the composite electrode, in order to observe the effect of pre-treatment. Also given are the standard electron transfer rate constants using the electroactive areas, calculated as described in [29].

As expected, the electroactive area of the composite electrode is smaller than the geometric area, given that conductor-insulator type composite electrodes consist of a random mixture of conduc- tive and non-conductive areas. As can be seen from Table 3, the electroactive area of the CA-graphite electrode increased substantially after polishing the surface, which is probably mostly due to removal of the CA insulating polymer. At the same time, the electrode surface became smoother and more homogenous, passing from the initial rough surface to a metal shining smoother surface. After surface polishing, an electroactive area of almost $70 \%$ of the geometric area suggests that, for this composite, the electrode surface consists in large conducting regions.

\subsection{Electropolymerisation of neutral red}

The phenazine dye neutral red (NR) has been used extensively by us for the preparation of electropolymerised poly(neutral red) films on carbon film substrates, and which have been characterised using electrochemical methods [26,34]. The polymer film has been successfully used as redox mediator in various biosensor assemblies $[25,26]$. Thus, it was chosen to electropolymerise NR also on CA-graphite composite electrodes, in order to observe the influence of the type of carbon substrate on both the electropolymerisation process and on the polymer film characteristics. Fig. 4 shows cyclic voltammograms recorded under the same experimental conditions, at a composite electrode and at a carbon film electrode (see also [34]).

The neutral red monomer electropolymerises more readily at CA-graphite composite than at carbon film electrodes, reflected in higher currents and greater increases of the oxidation and reduction peak current during electropolymerisation. It is also observed that, while in the case of carbon film electrodes, the increase in anodic and cathodic peak values occurs only up to the seventh-eighth cycle, in the case of the composite electrode they increase up to the last electropolymerisation cycles. No substantial differences were observed in the anodic and cathodic peak potential values, the only difference being that, in the case of composite electrode, the cathodic peak value does not shift to negative values with polymer formation, as is observed when carbon film electrodes are used.

These results suggest a higher stability of the polymer film formed which could be important for PNR-mediated biosensors that are used repetitively over a period of time.

\subsection{Characterization of the composite electrodes by EIS}

Electrochemical impedance spectroscopy (EIS) was used to characterize the physical and interfacial properties of the conducting composite material. Spectra recorded at both polished and unpolished electrodes, at applied potentials between -1.0 and $1.0 \mathrm{~V}$ vs. SCE in $0.1 \mathrm{M}$ NaPBS pH 7.0 buffer solution are shown in Fig. 5 . The form of the spectra for both types of electrode is similar at all applied potentials tested indicating a relatively high resistance and capacitance of the composite material, with a stable response over the whole potential range. The shapes of the spectra for unpolished electrodes show a small curvature and after surface polishing they become straight lines, suggesting increased capacitive characteristics.

Table 3

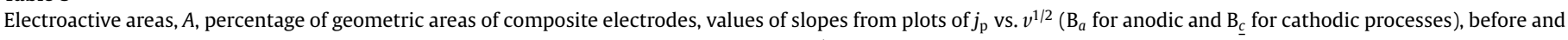

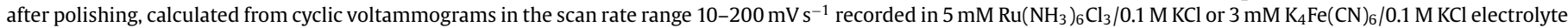
solution.

\begin{tabular}{|c|c|c|c|c|}
\hline \multirow[t]{2}{*}{ Electroactive species } & \multicolumn{2}{|c|}{ Unpolished electrodes } & \multicolumn{2}{|c|}{ Polished electrodes } \\
\hline & $\mathrm{Ru}\left(\mathrm{NH}_{3}\right)_{6} \mathrm{Cl}_{3}$ & $\mathrm{~K}_{4} \mathrm{Fe}(\mathrm{CN})_{6}$ & $\mathrm{Ru}\left(\mathrm{NH}_{3}\right)_{6} \mathrm{Cl}_{3}$ & $\mathrm{~K}_{4} \mathrm{Fe}(\mathrm{CN})_{6}$ \\
\hline$A\left(\mathrm{~cm}^{2}\right)$ & $0.105 \pm 0.007$ & $0.110 \pm 0.010$ & $0.175 \pm 0.005$ & $0.175 \pm 0.004$ \\
\hline \%Geometric area & 42 & 44 & 70 & 70 \\
\hline $\mathrm{B}_{a}$ & 62.6 & 35.3 & 78.6 & 44.3 \\
\hline $\mathrm{B}_{c}$ & 54.8 & 32.6 & 78.2 & 39.6 \\
\hline$k_{0} \times 10^{5}\left(\mathrm{~cm} \mathrm{~s}^{-1}\right)$ & 4.0 & 8.3 & 7.0 & 10.2 \\
\hline
\end{tabular}



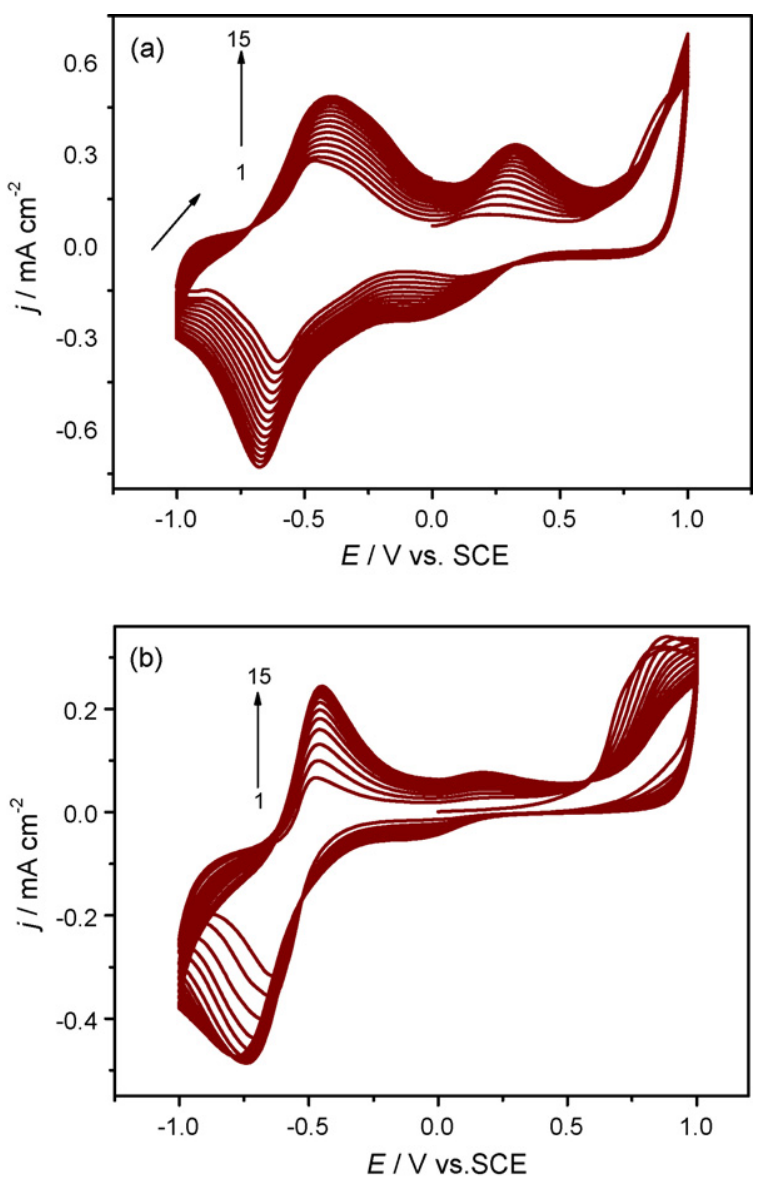

Fig. 4. Electropolymerisation of neutral red on (a) CA-graphite composite electrode and (b) carbon film electrode from a solution containing $1 \mathrm{mM}$ NR in $0.025 \mathrm{M}$ KPBS $\mathrm{pH} 5.5$; scan rate $50 \mathrm{mV} \mathrm{s}^{-1}$. Current values are normalized to electroactive areas.

For an insulator/conducting-composite electrode, the nonhomogeneity and roughness of the electrode surface, with randomly distributed conducting particles in a three dimensional insulating polymer matrix means that a constant phase angle element (CPE) can be conveniently used to replace interfacial capacitance. It has been widely used in equivalent circuit fitting for composite or porous electrodes e.g. [35-37].

The equivalent circuit proposed to fit the EIS results is similar to that proposed for other conductor-insulator composite electrodes [37] except that the constant phase element $\mathrm{CPE}_{2}$ is replaced with a pure capacitor $C_{2}$. The equivalent circuit shown in Fig. $5 c$ consists of the cell resistance, $R_{\Omega}$, (value $23 \pm 1 \Omega \mathrm{cm}^{2}$ ), in series with a constant phase element, $\mathrm{CPE}_{1}=\left\{(\mathrm{Ci} \omega)^{n}\right\}^{-1}$, representing the interfacial charge separation, modelled as a non-ideal capacitor, in parallel with a polarization resistance, $R_{1}$, and an intrinsic material capacitance, $C_{2}$. Other equivalent electrical circuits were also tested, but fitting was not possible.

The variation of $R_{1}, \mathrm{CPE}_{1}$ and $C_{2}$ values with applied potential calculated by fitting impedance spectra recorded at two different unpolished $\left(\mathrm{CE}_{1}\right.$ and $\left.\mathrm{CE}_{2}\right)$ and two different polished $\left(\mathrm{CEp}_{1}\right.$ and $\mathrm{CEp}_{2}$ ) composite electrodes are shown in Fig. 6. It can be seen that the variations in behaviour are the same for the two electrodes.

Both unpolished electrodes have a similar resistance, $R_{1}$, at all applied potentials. The unpolished electrode $\mathrm{CE}_{1}$ exhibits a value of $R_{1}$ of $0.26 \mathrm{k} \Omega \mathrm{cm}^{2}$ at $-0.8 \mathrm{~V}$ which then decreases slightly to $0.24 \mathrm{k} \Omega \mathrm{cm}^{2}$ at $0.0 \mathrm{~V}$ and then increases to $0.36 \mathrm{k} \Omega \mathrm{cm}^{2}$ at $+0.8 \mathrm{~V}$ vs. SCE. The other unpolished electrode shows the same variation of resistance with applied potential, with slightly higher values, prob- ably due to differences in graphite geometric area. After polishing the electrodes, an increase in $R_{1}$ values, normalised by the geometric area, was observed together with a change in the variation with applied potential, attributed to the change in exposed surface area and to the different composition of the exposed electrode surface - the exposed surface area (as opposed to the geometric surface area) will be reduced on polishing which could lead to an apparent increase in $R_{1}$ values that are normalised by geometric area. Maximum values of $0.89 \mathrm{k} \Omega \mathrm{cm}^{2}$ and $1.28 \mathrm{k} \Omega \mathrm{cm}^{2}$ at -0.6 and $+0.6 \mathrm{~V}$ vs. SCE, respectively occur for $\mathrm{CEp}_{1}$, that can be correlated with oxidation and reduction of carbon species [27]. This was not observed for unpolished electrodes, probably because of a
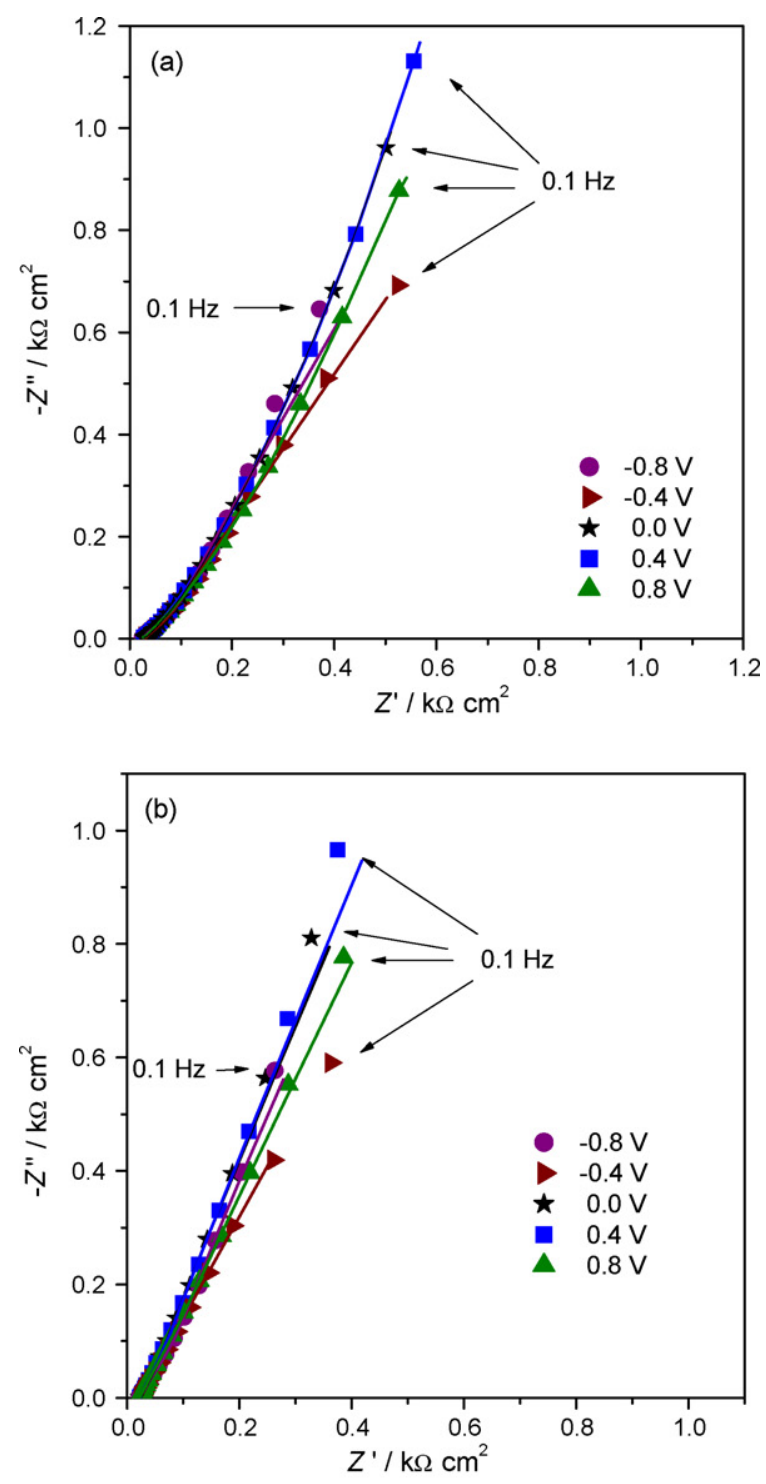

(c)

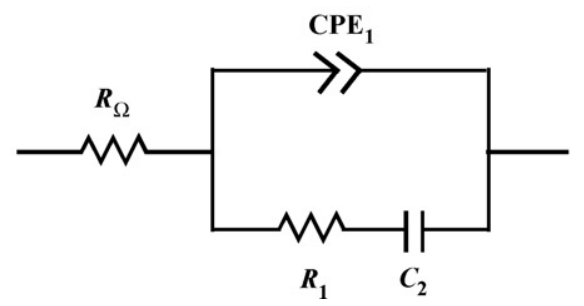

Fig. 5. Complex plane impedance plots recorded in $0.1 \mathrm{M} \mathrm{NaPBS}+0.05 \mathrm{M} \mathrm{NaCl} \mathrm{pH}$ 7 buffer solution, at (a) unpolished and (b) polished electrodes. The lines show the fitting to the equivalent circuit in (c) (see text for meaning of symbols). 

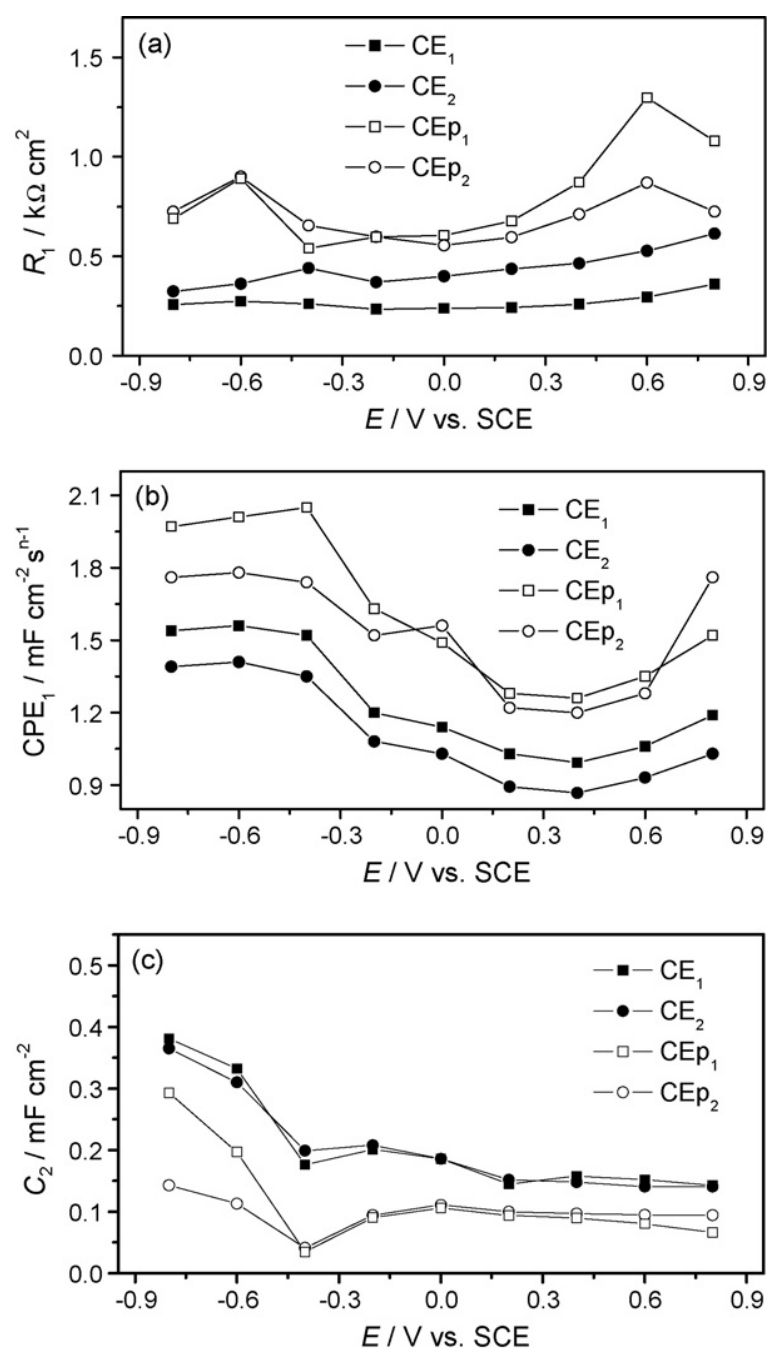

Fig. 6. Variation with applied potential of (a) $R_{1}$ (b) CPE and (c) $C_{2}$ values calculated by fitting impedance spectra at two unpolished $\left(\mathrm{CE}_{1}, \mathrm{CE}_{2}\right)$ and two polished $\left(\mathrm{CEp}_{1}\right.$, $\mathrm{CEp}_{2}$ ) composite electrodes in $0.1 \mathrm{M} \mathrm{NaPBS}+0.05 \mathrm{M} \mathrm{NaCl} \mathrm{pH} 7$.

higher coverage of the exposed electrode surface with CA insulating polymer.

The $\mathrm{CPE}_{1}$ values increased by $\sim 20 \%$ and the $n$ exponent values increased from $0.58 \pm 0.02$ to $0.70 \pm 0.03$ after surface polishing, which is expected due to the greater smoothness. The CPE value of $\mathrm{CE}_{1}$ remained constant at $1.5 \mathrm{mF} \mathrm{cm}^{-2} \mathrm{~s}^{n-1}$ from $-0.8 \mathrm{~V}$ to $-0.4 \mathrm{~V}$, then decreased to $1.0 \mathrm{mF} \mathrm{cm}^{-2} \mathrm{~s}^{n-1}$ at $+0.4 \mathrm{~V}$, increasing to $1.2 \mathrm{mF} \mathrm{cm}^{-2} \mathrm{~s}^{n-1}$ by $+1.0 \mathrm{~V}$ vs. SCE. The same profile of $\mathrm{CPE}_{1}$ dependence with potential was observed for $\mathrm{CE}_{2}$. The increase in $\mathrm{CPE}_{1}$ values after polishing the electrode surface can be explained by the fact that the electroactive area of the electrode is larger (see Section 3.4), allowing a faster charge and discharge of the interfacial double layer.

The capacitance, $C_{2}$, is associated with intrinsic capacitive properties of the composite material. The material behaves as an assembly of small capacitors, because of the conducting graphite grains randomly dispersed in the insulating polymer matrix. The material does not present significant changes in the intrinsic capacitance values with applied potential, from -0.4 to $0.8 \mathrm{~V}$, with a value of $\sim 0.15 \mathrm{mF} \mathrm{cm}^{-2}$ for the unpolished electrodes and $\sim 0.10 \mathrm{mF} \mathrm{cm}^{-2}$ in the case of polished electrodes. Below $-0.4 \mathrm{~V}$ the $C_{2}$ values begin to increase, which has also been observed in the case of $\mathrm{CPE}_{1}$ values, probably because of increased polarization of the material at these potentials. The unexpectedly high values of the intrinsic capaci- tance can be attributed to the roughness and some porosity of the electrode surface, which could lead to penetration of electrolyte into the material.

\subsection{Comparison of the CA-graphite composite with other carbon-based composite electrodes}

Some important quantitative properties of the new developed CA-graphite composite electrodes can be compared with those of other composite and carbon-paste-based electrodes. In Table 2 are presented accessible potential ranges for various carbon electrodes in acidic and neutral media. As observed, the new CA-graphite composite electrodes exhibit a much larger potential window, which is very valuable for their analytical application. Furthermore, the percentage of geometric area which is electroactive is $70 \%$ after polishing these new electrodes, much higher than other values found in the literature, e.g from $6.7 \%$ to $37 \%$ in the case of Kelgraf electrodes [30], or from $17 \%$ to $63 \%$ for epoxy-graphite composite electrodes [3]. This higher value of the electroactive area is principally due to the existence of the roughness of the electrode surface, which can provide a larger available electrode/solution interface area. In other work reported in the literature, the cyclic voltammograms of the $\mathrm{Fe}^{\mathrm{III}} / \mathrm{Fe}^{\mathrm{II}}$ redox couple yield poorly discernable redox peaks at conventional carbon paste electrodes [39], epoxy-graphite [3] or Teflon-graphite composite electrodes [38], while in the case of CA-graphite electrode very well defined redox peaks are recorded (see Fig. $2 \mathrm{a}_{2}$ ). Furthermore, the ratio of forward and backward peak currents for $\mathrm{Ru}^{\mathrm{III}} / \mathrm{Ru}^{\mathrm{II}}$ and $\mathrm{Fe}^{\mathrm{III}} / \mathrm{Fe}^{\mathrm{II}}$ redox systems is the closest to one and the electrochemical reversibility is better at the newlydeveloped electrodes.

\subsection{Determination of ascorbate at CA-graphite composite electrodes}

To demonstrate analytical application, the new composite electrodes were also applied to the amperometric determination of ascorbate in neutral media (0.1 M NaPBS pH 7.0) at different operating potentials selected on the basis of previous work using electrochemical sensors [40]. Cyclic voltammograms in the absence and presence of ascorbate are shown in Fig. 7. The analytical parameters calculated from calibration curves at $0.05,0.02$ and $0.00 \mathrm{~V}$ vs. SCE are given in Table 4 . As expected, at $0.05 \mathrm{~V}$ the sensitivity of the sensor was highest $\left(53.5 \pm 0.1 \mu \mathrm{AmM}^{-1} \mathrm{~cm}^{-2}\right)$, but even at $0.00 \mathrm{~V}$ vs. SCE the sensor gave a very good response with a sen-

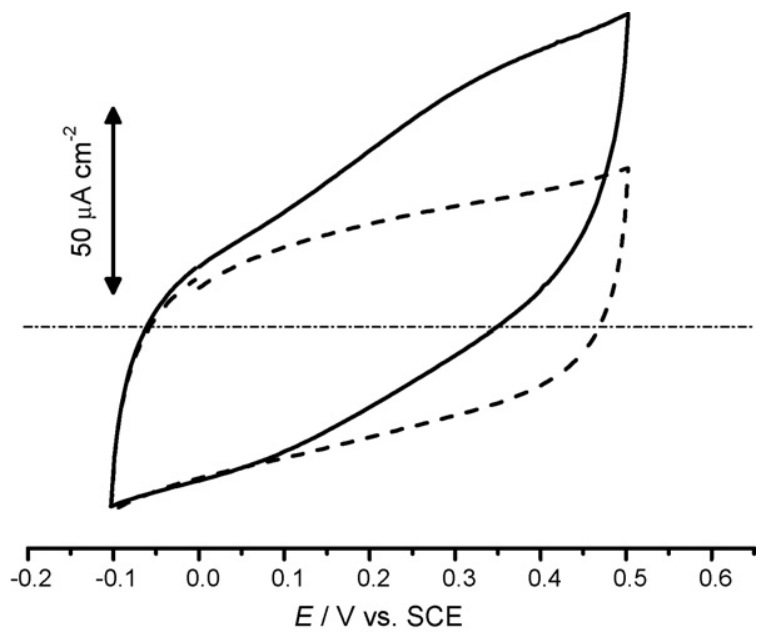

Fig. 7. Cyclic voltammograms in the absence (-- ) and presence (-) of $0.4 \mathrm{mM}$ ascorbate at a polished CA-graphite composite electrode in $0.1 \mathrm{M} \mathrm{NaPBS} \mathrm{pH}$ 7.0. Scan rate $50 \mathrm{mV} \mathrm{s}^{-1}$. 
Table 4

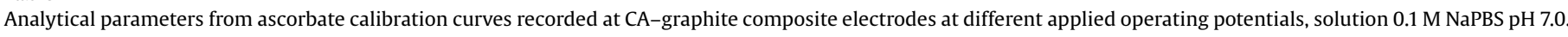

\begin{tabular}{|c|c|c|c|c|}
\hline Operating potential V vs. SCE & Sensitivity $\left(\mu \mathrm{Acm}^{-2} \mathrm{mM}^{-1}\right)$ & Intercept $\left(\mu \mathrm{A} \mathrm{cm}^{-2}\right)$ & $\operatorname{LOD}(\mu \mathrm{M})$ & Correlation coefficient $\left(R^{2}\right)$ \\
\hline 0.05 & $53.5 \pm 0.1$ & $0.25 \pm 0.10$ & $8.4 \pm 0.2$ & 0.99996 \\
\hline 0.02 & $36.0 \pm 0.1$ & $0.14 \pm 0.07$ & $9.2 \pm 0.2$ & 0.99987 \\
\hline 0.00 & $25.8 \pm 0.1$ & $0.12 \pm 0.05$ & $7.7 \pm 0.1$ & 0.99997 \\
\hline
\end{tabular}

sitivity of $25.8 \pm 0.1 \mu \mathrm{AmM}^{-1} \mathrm{~cm}^{-2}$, which is much higher than other sensors for ascorbate at potentials close to $0.0 \mathrm{~V}$ vs. SCE or $\mathrm{Ag} / \mathrm{AgCl}$ which exhibit sensitivities of the order of $2 \mu \mathrm{A} \mathrm{mM}^{-1} \mathrm{~cm}^{-2}$ $[40,41]$. The calculated detection limit was $7.7 \mu \mathrm{M}$, much lower than $50 \mu \mathrm{M}$ reported in [42] and comparable with those for amperometric sensors which detect ascorbate at more positive potentials with detection limits between 1.5 and $5 \mu \mathrm{M}[40,42,43]$.

In order to evaluate the accuracy and precision of the sensor, chronoamperograms were recorded with addition to the $0.1 \mathrm{M}$ NaPBS pH 7.0 buffer solution of aliquots of $10 \mu \mathrm{l}$ of $0.1 \mathrm{M}$ ascorbate standard solution or of $0.1 \mathrm{M}$ ascorbate solution obtained by dissolving a tablet of vitamin $C$ (Cecrisina ${ }^{\circledR}$ ) appropriately. It was observed that the sensor presents the same sensitivity for both ascorbate solutions; the calculated recovery was $99.3 \pm 0.2 \%$ (three measurements).

This data shows that measurements at CA-graphite composite electrodes are precise and this sensor can therefore be applied for ascorbate quantification in food or drinks.

\section{Conclusions}

Cellulose acetate-graphite composite electrodes have been developed with a large potential window in solutions in the $\mathrm{pH}$ range from 4.6 to 8.2. The composite electrodes give well-defined voltammetric responses for model electroactive species hexaammineruthenium(III) chloride and potassium hexacyanoferrate(II) in $0.1 \mathrm{M} \mathrm{KCl}$ with a low relative standard deviation of less than $4 \%$ between electrodes. Polishing the composite electrode surface and electrochemical pre-treatment both improved the electrochemical characteristics and increased their electroactive area. Neutral red polymerises successfully. The electrochemical impedance results are in agreement with the material being an assembly of microelectrodes acting as microcapacitors in the region where no oxidation or reduction reactions occur.

The CA-graphite electrodes were successfully employed as amperometric sensors for ascorbate detection in neutral media at $0.0 \mathrm{~V}$ vs. SCE.

This work has demonstrated the good characteristics of this new type of mechanically flexible and robust composite electrode, using a cellulose acetate matrix, which can easily be prepared in desired sizes. Their adaptability means that diverse applications in electrochemical sensors and biosensors can be expected.

\section{Acknowledgements}

Financial support from Fundação para a Ciência e a Tecnologia (FCT), PTDC/QUI/65255/2006 and PTDC/QUI/65732/2006, POCI 2010 (co-financed by the European Community Fund FEDER) and CEMUC $^{\circledR}$ (Research Unit 285), Portugal, is gratefully acknowledged. FCT is thanked for PhD grants for MMB (SFRH/BD/27864/2006) and $\operatorname{EMP}($ SFRH/BD/31483/2006).

\section{References}

[1] R.N. Adams, Anal. Chem 30 (1958) 1576.

[2] S. Ramírez-García, S. Alegret, F. Céspedes, R.J. Forster, Analyst 127 (2002) 1512.

[3] D. O’Hare, J.V. Macpherson, A. Willows, Electrochem. Commun. 4 (2002) 245.

[4] K. Kalcher, J.M. Kauffmann, J. Wang, I. Svankara, K. Vytras, C. Neuhold, Z. Yang, Electroanalysis 7 (1995) 5

[5] F. Céspedes, E. Martínes-Fábregas, S. Alegret, Trends Anal. Chem. 15 (1996) 296.

[6] D.E. Tallman, S.L. Petersen, Electroanalysis 2 (1990) 499.

[7] S. Ramírez-García, F. Céspedes, S. Alegret, Electroanalysis 13 (2001) 529.

[8] A. Morales, F. Céspedes, S. Alegret, Mater. Sci. Eng. C 7 (2000) 99.

[9] R.H. Carvalho, F. Lemos, M.A.N.D.A. Lemos, J.M.S. Cabral, F. Ramôa Ribeiro, J Mol. Catal. Chem. 278 (2007) 47.

[10] S.J.R. Prabakar, S.S. Narayanan, Talanta 72 (2007) 1818.

[11] K. Stulík, Electroanalysis 4 (1992) 829.

[12] F. Abertús, A. Llerena, J. Alpízar, V. Cerdá, M. Luque, A. Ríos, M. Valcárcel, Anal. Chim. Acta 355 (1997) 23.

[13] M. Luque, A. Ríos, M. Valcárcel, Anal. Chim. Acta 395 (1999) 217.

[14] R. Aguilar, M.M. Dávila, M.P. Elizalde, M. Mattusch, R. Wennrich, Electrochim. Acta 49 (2004) 851.

[15] T.R.I. Cataldi, D. Centonze, Anal. Chim. Acta 307 (1995) 43.

[16] Ü.A. Kirgöz, D. Odaci, S. Timur, A. Merkoçi, N. Pazarlioğlu, A. Telefoncu, S. Alegret, Bioelectrochemistry 69 (2006) 128.

[17] Ü.A. Kirgöz, D. Odaci, S. Timur, A. Merkoçi, S. Alegret, N. Beşün, A. Telefoncu, Anal. Chim. Acta 570 (2006) 165.

[18] E. Zacco, M.I. Pividori, X. Llopis, M. del Valle, S. Alegret, J. Immunol. Methods 286 (2004) 35

[19] M.I. Pividori, A. Merkoçi, S. Alegret, Biosens. Bioelectron. 19 (2003) 473.

[20] A.B. Florou, M.I. Prodromidis, M.I. Karayannis, S.M. Tzouwara-Karayanni, Electroanalysis $12(2000) 361$.

[21] J. Tkák, I. Voštiar, E. Šturdík, P. Gemeiner, V. Mastihuba, J. Annus, Anal. Chim Acta 439 (2001) 39.

[22] A. Moody, S. Setford, S. Saini, Analyst 126 (2001) 1733.

[23] A.B. Florou, M.I. Prodromidis, M.I. Karayannis, S.M. Tzouwara-Karayanni, Anal. Chim. Acta 409 (2000) 113.

[24] C.A. Borgo, A.M. Lazarin, Y. Gushikem, Sens. Actuators B 87 (2002) 498.

[25] M.E. Ghica, C.M.A. Brett, Electroanalysis 18 (2006) 748.

[26] R. Pauliukaite, M.E. Ghica, M. Barsan, J. Solid State Electrochem. 11 (2007) 899.

[27] O.M.S. Filipe, C.M.A. Brett, Electroanalysis 16 (2004) 994.

[28] N. Peña, G. Ruiz, A.J. Raviejo, J.M. Pingarrón, Anal. Chem. 73 (2001) 119.

[29] C.M.A. Brett, A.M. Oliveira Brett, Electrochemistry: Principles Methods and Applications, Oxford University Press, Oxford, 1993, Chapter 9.

[30] D.E. Welsshaar, D.E. Tallman, Anal. Chem. 55 (1983) 1146.

[31] M.R. Deakin, K.J. Stutts, R.M. Wightman, J. Electroanal. Chem. 182 (1985) 113.

[32] A.B. Florou, M.I. Prodromidis, M.I. Karayannis, S.M. Tzouwara-Karayanni, Electroanalysis 10 (1998) 1261.

[33] K. Wang, J. Lu, L. Zuang, J. Electroanal. Chem. 585 (2005) 191.

[34] M.M. Barsan, E.M. Pinto, C.M.A. Brett, Electrochim Acta 53 (2008) 3973.

[35] L. Beaunier, M. Keddam, J.J. García-Jereño, F. Vicente, J. Navaro-Laboulais, J. Electroanal. Chem. 566 (2004) 159.

[36] D. Savitri, C.K. Mitra, Bioeletrochem. Bioenerg. 48 (1999) 163.

[37] J. Navarro-Laboulais, J. Trijueque, J.J. García-Jareño, D. Benito, F. Vicente, J. Electroanal. Chem. 444 (1998) 173.

[38] L.N. Klatt, D.R. Connell, R.E. Adams, Anal. Chem. 47 (1975) 2470.

[39] P. Fanjul-Bolado, D. Hernández-Santos, P.J. Lamas-Ardisana, A. Martín-Pernía A. Costa-García, Electrochim. Acta 53 (2008) 3635.

[40] R. Paulikaite, M.E. Ghica, C.M.A. Brett, Anal. Bioanal. Chem. 381 (2005) 972.

[41] J.Y. Heras, A.F.F. Giacobone, F. Battaglini, Talanta 71 (2007) 1684.

[42] I. Jurevičiūtè, K. Brazdžiuvienè, L. Bernotaitè, B. Šalkus, Sens. Actuators B 107 (2005) 716.

[43] K. Brazdžiuvienè, I. Jurevičiūtè, A. Malinauskas, Electrochim. Acta 53 (2007) 785 . 